\title{
Postextraction Implant Placement with Immediate Provisionalisation and Finalisation, Using a Simplified Technique: Technical Notes and a Case Report
}

\author{
Rudy Scala ${ }^{1}$, Paolo Ghensi ${ }^{2, *}$, Alessandro Cucchi $^{2}$ and Enrico Pistoia ${ }^{1}$ \\ ${ }^{1}$ University of Verona, Faculty of Medicine, Dentistry and Maxillofacial Surgery Clinic, Verona, Italy \\ ${ }^{2}$ University of Milan, Faculty of Medicine, Dentistry Clinic, Milan, Italy. Private Dentist, Trento, Italy
}

\begin{abstract}
Trauma of maxillary teeth is a common accident. In most cases, the result is a root or crown fracture requiring tooth extraction and implant placement. Immediate postextraction implants are considered an effective option for restoring missing teeth in order to achieve successful aesthetic and functional outcomes. The aim of this article is to describe a clinical case in which a fractured maxillary canine was replaced by an osseointegrated implant using a simplified technique in a patient who was a smoker and presented poor oral hygiene. The technique adopted permits a reduction of the number of implant components and consequently a lower cost of treatment, while at the same time maintaining acceptable aesthetic and functional outcomes.
\end{abstract}

Keywords: Immediate loading, postextraction implant, mount, flapless.

\section{INTRODUCTION}

In implant dentistry the concept of osseointegration was first introduced by Brånemark in 1964, and the guidelines for obtaining a direct connection between bone and titanium were described in 1977 by the same author [1]. A stress-free healing period is generally recommended to achieve osseointegration of dental implants without interposition of fibrous scar tissue [1]. In addition, the traditional guidelines recommend a six- to twelve-month healing period for the alveolar bone following tooth extraction $[2,3]$.

A number of authors have introduced protocols that involve immediate implant placement and provisionalisation following tooth extraction. Although high survival rates for implants with these operative protocols are reported in several studies, postoperative complications such as gingival shrinkage and bone resorption in aesthetically important areas are an important limitation. Continued bone and soft tissue loss may also cause exposure of the implant surface resulting in a compromised aesthetic outcome $[4,5]$. These techniques make it possible to reduce the time required to restore a lost tooth from 9 to 18 months. The advantages of immediate implant placement include a reduction in treatment time, a reduction of surgical procedures and a reduction of aesthetic rehabilitation time [6,7].

The principal indications for immediate postextraction implant placement are tooth fracture, periodontal support loss, radicular caries, endodontic failures and non-restorable crowns [8].

*Address correspondence to this author at the Via Chini 101/2, Trento, (TN) Italy; Tel: +390461910569; E-mail: dr.ghensi@gmail.com
The immediate replacement of the lost root prevents the loss of alveolar bone in height and width [9]. The results of extraction are well known: $40 \%$ to $60 \%$ alveolar bone loss in the first 2 to 3 years and a resorption rate of $0.5 \%$ to $1 \%$ every year for the rest of the patient's life $[10,11]$.

Owing to the geometric discrepancy between the extraction socket and implant design, immediate placement frequently requires bone augmentation. Larger diameter implants, possibly combined with guided bone regeneration, have been advocated to address this discrepancy $[8,12,13]$. The alveolar socket is generally filled with the dental implant, deproteinised heterologous bone and autologous bone obtained during alveolus preparation; the graft is necessary to reduce the gap between the implant and the alveolar bone and to accelerate the new bone apposition process [14].

Conical implants with internal hexagonal extensions present many advantages: the internal hexagon is an aesthetic solution because it allows the placement of a smaller abutment upon a larger implant, permitting a thicker layer of ceramic crown and a better filling of the alveolar socket, respectively. The conical design induces tight contact with the adjacent bone tissue and osseointegration with intimate bone contact over the whole length of the implant.The placement of larger diameter implants requires the positioning of a smaller amount of autologous or heterologous material, and facilitates the compression and condensation of the graft on the walls of the alveolar socket $[15,16]$.

The aim of this article is to describe a clinical case in which a fractured maxillary canine was replaced by an immediately loaded postextraction implant using a simplified technique, which permits a reduction of the number of implant components and consequently a lower cost of treat- 


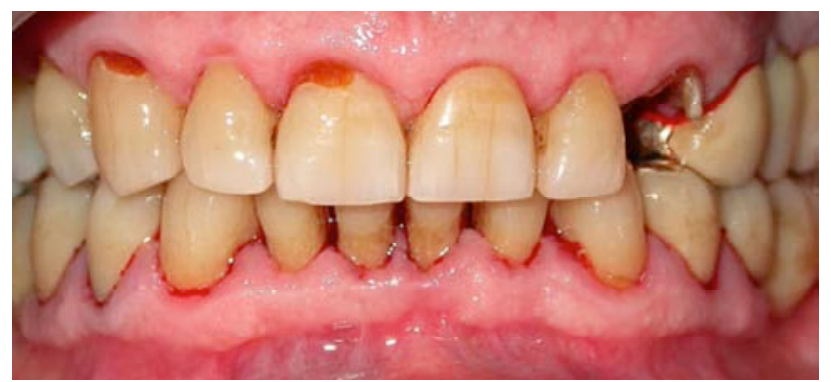

Fig. (1). Preoperative oral condition: it is noticeable thenonrestorable left maxillary canine.

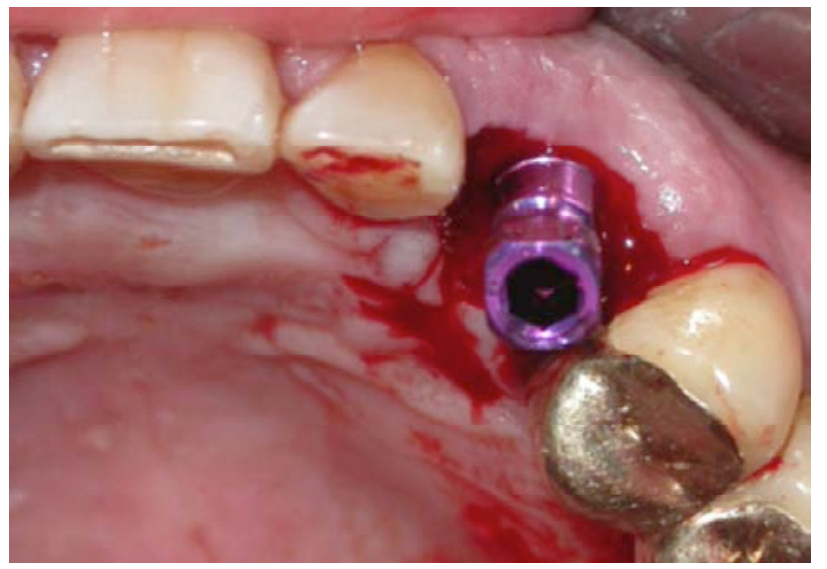

Fig. (2). Implant with mount.

ment, while at the same time maintaining acceptable aesthetic and functional outcomes.

\section{CASE REPORT}

A 68-year-old male patient with a number of contraindications to treatment, such as smoking ( $>10$ cigarettes/day) and chronic periodontitis, was referred to the Dentistry and Maxillofacial Surgery Clinic of the University of Verona with a non-restorable left maxillary canine to be removed due to a crown fracture (Fig. 1). The patient expressed his desire to have a rehabilitation that could offer a satisfactory aesthetic outcome at a lower cost. Treatment options were reviewed, and informed consent was obtained. Based on the patient's express desire to reduce the treatment time, we decided to perform a postextraction implant placement with immediate provisionalization since his clinical and radiographic examinations revealed ideal hard and soft tissue contours for this procedure.

A preliminary impression of the maxillary arch was made with alginate (Kromopan; LascodSpa, Sesto Fiorentino, Italy), a diagnostic waxing was prepared on the maxillary cast, and a provisional crown was fabricated for immediate provisionalisation of the implant.

Before starting the surgical procedure, in order to permit the growth of soft tissue above the root, soft tissue was abraded and the residual crown was smoothed and cut down with a rosette bur. This provided more voluminous gingival tissue, making it possible to create a correct appearance profile on the part of the gingival architecture.

On the day of surgery the patient received $2 \mathrm{~g}$ of amoxicillin 1 hour before surgery, chlorhexidine and $1 \mathrm{~g}$ of amox-

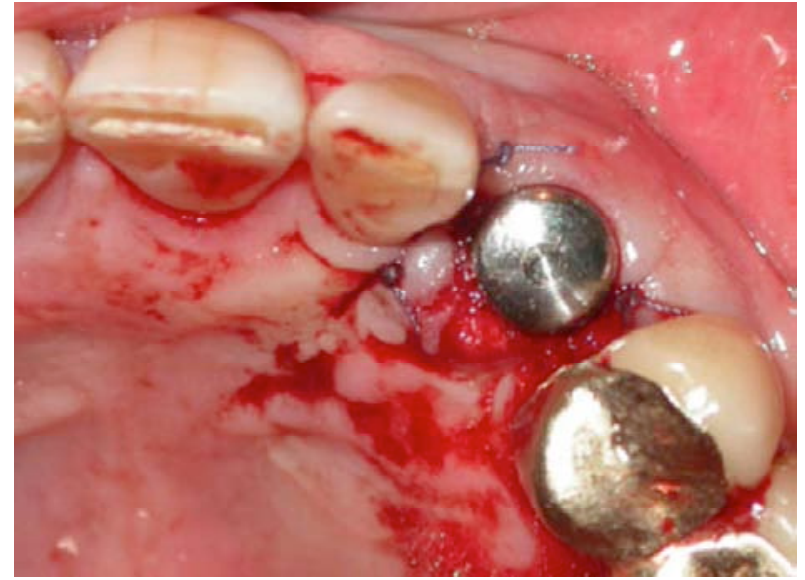

Fig. (3). Implant with healing abutment and suture around implant.

icillin 6 hours after surgery to reduce the risk of infection. Local anaesthetic was injected into the oral mucosa and palatally (2\% mepivacain with epinephrine 1:100000; Monico Spa, Venice, Italy). An atraumatic extraction was performed without flap elevation to preserve the integrity of the interproximal papillae and remaining buccal and lingual bone plates. The tooth was carefully extracted using a luxator and forceps, the extraction being accomplished with light twisting movements to avoid breaking the bony margins of the alveolus. The extraction socket was debrided using a manual instrument and was irrigated with sterile saline. The alveolus showed the absence of fenestrations or dehiscences of the bone walls and $\mathrm{a} \leq 2 \mathrm{~mm}$ residual gap between the implant surface and surrounding bone walls. The implant site was prepared at the bottom of the socket according to standard procedures .A conical implant with an MP-1 hydroxyapatite surface (Tapered Screw-Vent System; Zimmer Dental, USA) was placed completely within the confines of the socket using the sterile surgical technique prescribed by the manufacturer (Fig. 2). Evaluating the three dimensions, the implant was guided by the provisional restoration using a surgical template to achieve the optimal prosthetic position. The implant shoulder was positioned $1.5-2 \mathrm{~mm}$ from the adjacent teeth, $3 \mathrm{~mm}$ apical to the anticipated gingival margin, and 1 $\mathrm{mm}$ apical to the height of the most coronal wall of the alveolus. After placement of the implant a marginal defect area surrounding the implant was identified, measured as a distance of $1.5 \mathrm{~mm}$ mid-buccally and $1.2 \mathrm{~mm}$ mid-palatally.In order to obtain bone regeneration and bone integration in the circumferential defect area, autologous bone obtained during implant site preparation was lightly packed into the alveolus and then compressed and condensed by the implant placement; the residual gap was filled with a gelatin sponge (Antema; Opocrin Spa, Modena, Italy). The implant was inserted with a torque of $35 \mathrm{Ncm}$ to obtain optimal primary stability. After insertion the implant was first unscrewed and later screwed to control the torque between 35 and $50 \mathrm{Ncm}$ and to permit appropriate passivity of the implant in the prepared site (Figs. 2 and $\mathbf{3}$ ).

A mount was prepared and refined to create an abutment, which was positioned on the implant. A provisional composite resin crown was then positioned on the abutment previously created with assessment of adjacent tooth reference points (occlusal stops) and was fixed in the correct position, 


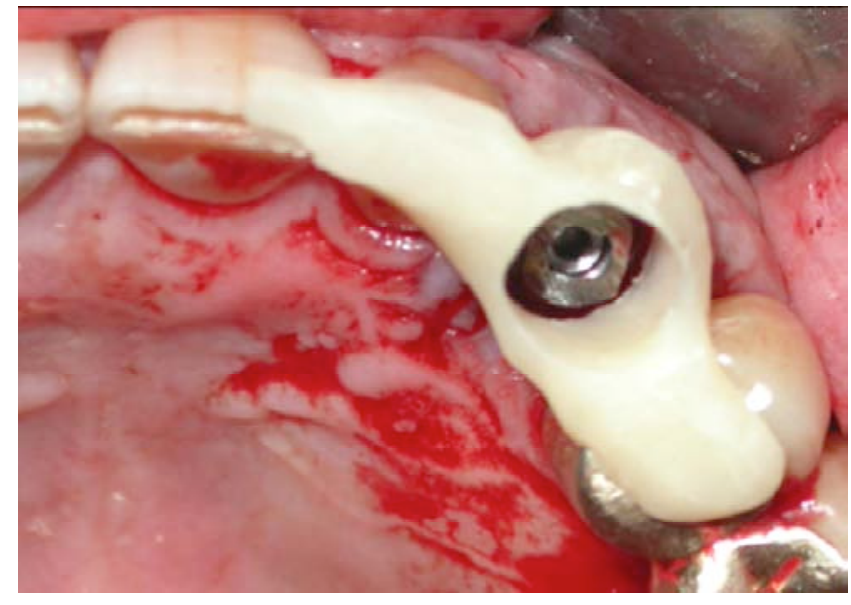

Fig. (4). Provisional resin prosthesis with occlusal stop.

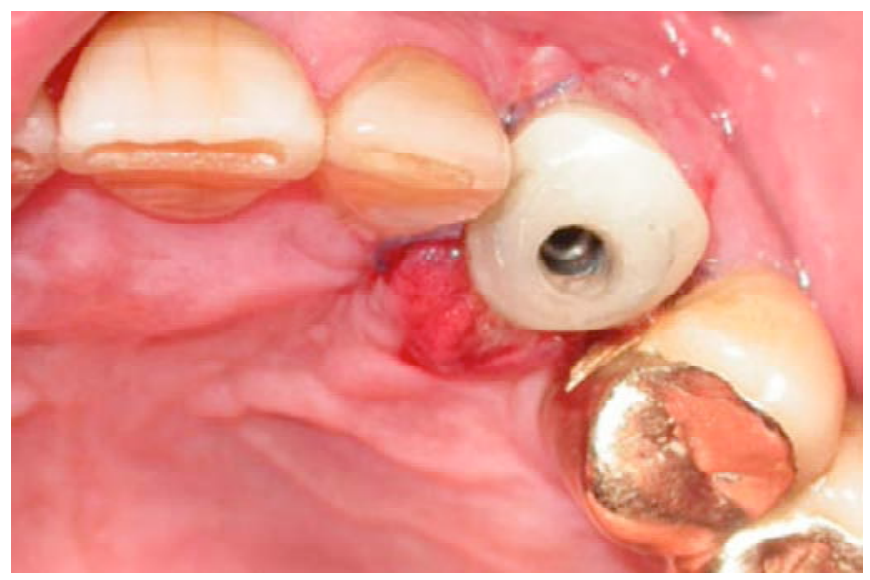

Fig. (5). Provisional prosthesis cemented with flowable composite resin.

filling the gap between the provisional crown and the abutment with flowable composite resin (Fig. 4). In this way the provisional crown and the abutment were united to form a single structure. This was subsequently removed from the implant to eliminate the occlusal stops and refine and contour the surface profile so as to achieve proper adaptation of the gingival soft tissue. The occlusion was adjusted to clear all contacts in maximum intercuspation and in lateral and protrusive excursions: any occlusal contacts during centric and eccentric movements on the provisional restoration were eliminated. The screw-retained structure was connected to the implant to allow maturation and integration of the periimplant soft tissues and to facilitate osseointegration (Fig. 5).

The patient was instructed to consume a soft diet and to avoid placing food in the surgical area during the first 6 weeks and was instructed to rinse twice daily with $0.2 \%$ chlorhexidinedigluconate (Periogard 0.2\%, Colgate, Sydney, Australia) and avoid brushing the surgical site for the first 2 weeks. He was also given amoxicillin $1 \mathrm{~g}$ every 8 hours for one week and non-steroidal-anti-inflammatory drugs for 5 days.

Five weeks after surgery the soft tissues showed a favorable healing pattern with no inflammation, no recession, and preservation of the interdental papillae (Figs. 6 and 7).

The screw-retained structure was removed from the implant and another mount was connected to the implant to

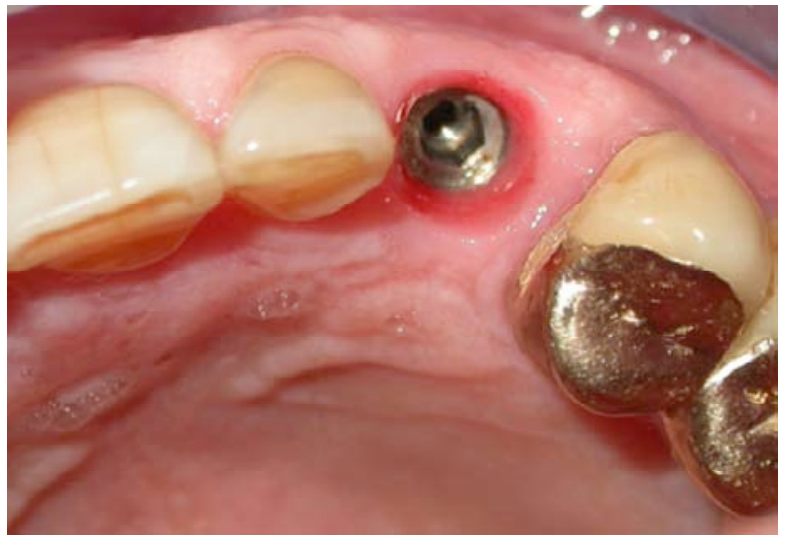

Fig. (6). Soft tissue after one week.

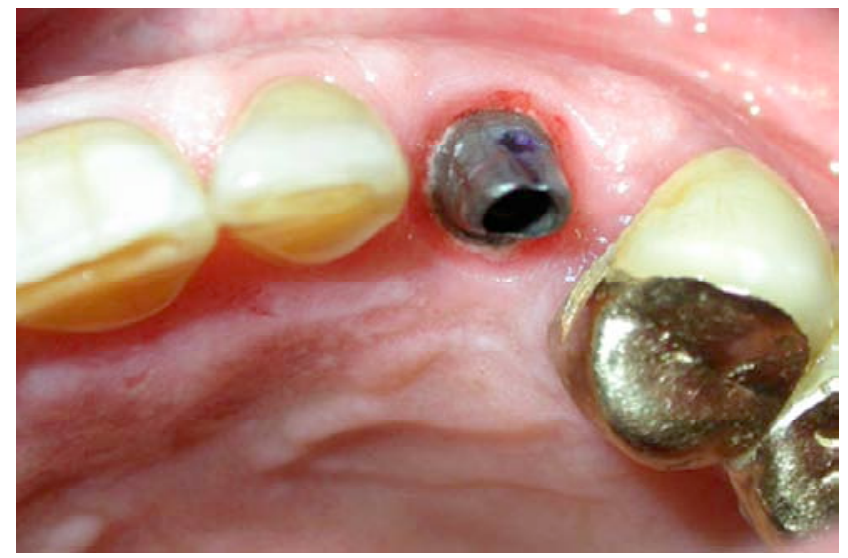

Fig. (7). Soft tissue after five weeks and definitive abutment.

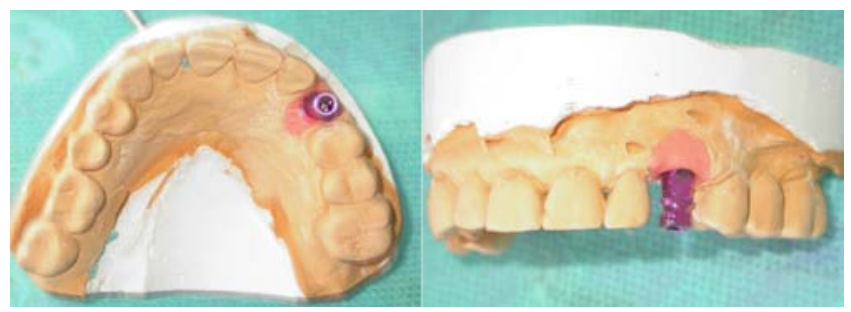

Fig. (8). Master model and mount (occlusal and lateral view).

function as a transfer abutment for impressions. A definitive impression was made using a polyether material (Integrum, ESPE Neuss, Germany) and was sent to a laboratory, where a master model was obtained from the impression (Fig. 8).

A definitive abutment was prepared from the mount and refined, and a definitive metal-ceramic crown was created for aesthetic finalisation. The definitive abutment was positioned and screwed to the implant, and the definitive crown was positioned and cemented onto the abutment (Fig. 9). The morphology of the occlusal surfaces was similar to that of natural teeth with occlusal contacts in maximum intercuspation and cusp inclination, and with functional contacts during lateral and protrusive excursions. The definitive restoration was placed seven weeks after implant placement.

When monitored at three months and one year, the hard tissues also showed a favourable healing pattern with no radiolucency around the implant and no resorption of the alveolar ridge. Post-surgical follow-up visits and professional oral hygiene were carried out at months $1,3,6,12,18$, 


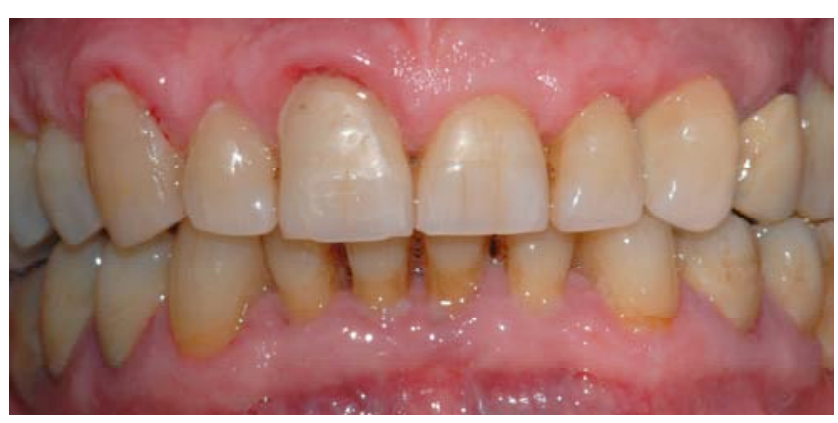

Fig. (9). Postoperative oral condition: it is noticeable the definitive left maxillary canine.

and 24 after the surgical procedure. At each follow-up visit a clinical evaluation was performed, and an intraoral radiograph was obtained using a customised right-angle holder. At month 24, the clinical and radiographic parameters were optimal: the interproximal papilla and gingival buccal margin levels remained stable, and the interproximal bone level also showed no change over this period of time.

\section{DISCUSSION}

This clinical case shows that an immediate implant restoration placed in a postextraction site can constitute a safe and successful treatment procedure. Several authors have shown that immediately loaded postextraction implants have a survival rate of $94.5-100 \%$ after twelve months of follow-up $[12,17-20]$.

Correct clinical, prosthetic and surgical management of endosseous implants replacing missing teeth in the anterior maxilla enables the dental surgeon to achieve predictable aesthetic outcomes. The immediate placement in postextraction sites is a surgical option capable of ensuring ideal periimplant tissue healing, while at the same time preserving the pre-surgical gingiva and bone $[21,22]$. To achieve prosthetic success, it is essential to understand the patient's expectations and desires, paying particular attention to his or her psychological and socio-economic status, as well as to his or her oral condition [23]. The prosthesis should integrate itself from the biological, functional and aesthetic points of view [24]. Some patients seek a rehabilitation capable of yielding the best aesthetic outcome possible despite the cost, whereas others request a rehabilitation capable of affording a satisfactory aesthetic result at a lower cost [25]. In cases such as the one reported here, we propose a simplified technique, which makes it possible to reduce the number of implant components and materials involved, and consequently to reduce the cost of treatment, while maintaining acceptable aesthetic and functional outcomes.

The technique described in this report is characterised by the immediate loading of a conical implant in a postextraction site, with no flap elevation, filling the socket not with heterologous bone but with a fibrin sponge, the use of a mount as transfer and abutment, and finalisation with a metal-ceramic crown.

The advantages of placing implants in fresh extraction sockets and putting them in immediate/early function are many. A predictable protocol affords the possibility of performing a single surgical procedure, giving the patient a temporary prosthesis immediately, and minimising the shrinkage of hard tissue and soft tissue recession [18]. There is a risk of mucosal recession and adverse soft tissue aesthetics with immediate implant placement. However, this risk may be reduced by avoiding a buccal position of the implant in the extraction socket [26].

Immediate provisionalisation of dental implants enables the patient to avoid the physical discomfort of wearing a removable interim prosthesis or the psychological trauma of a compromised smile [27]. The provisionalisation makes it possible to condition implant soft tissues in order to preserve the interproximal papillae and restore a curved/rounded appearance of the gingival margin; it also permits immediate healing of the soft tissue with the formation of an adequate mucosal seal [28]. For a predictable aesthetic result, an important aspect seems to be the height and thickness of the buccal bone wall, which remains after immediate placement of the fixture [21]. The immediate replacement of the missing root with a postextraction implant avoids the loss of bone in height and width [9].

After tooth extraction, there is a geometric discrepancy between the extraction socket and the implant design. Larger diameter implants, possibly combined with guided bone regeneration, have been advocated to address this discrepancy $[8,12]$. Tapered screw-vent implants have a larger coronal diameter that permits a survival rate of $98.5 \%$ for all implants placed, with no discernible bone loss in $88 \%$ of surviving implants, $1 \mathrm{~mm}$ of bone loss in $10.5 \%$ implants and 2 $\mathrm{mm}$ of bone loss in the remaining implants [29]. Other studies have demonstrated a survival rate of 96.6-98.6\% for tapered screw-vent implants and a crestal bone loss of 0.2-0.5 $\mathrm{mm}[30,31]$.

Heterologous bone would appear to significantly reduce horizontal resorption of buccal bone, but not to significantly reduce vertical resorption [26]. In our case the use of a tapered implant with a larger diameter and autologous bone chips was enough to fill most of the gap between the alveolar crest and the implant and to prevent horizontal and vertical bone loss; the rest of the gap was filled with a gelatin sponge in order to avoid the use of heterologous bone and consequently obtain a reduction of the total cost. During postextraction implant placement, it is not necessary to use heterologous bone to achieve a high success rate, especially in cases presenting a minimal residual discrepancy [19].

Flapless implant placement permits a reduction of bone resorption, which occurs when periostal tissue is separated from underneath cortical bone. Moreover, it reduces surgical and post-surgical times, which are necessary to remove the stitches, and reduces total costs as a result of the non-use of scalpel blades, needles and thread [32, 33].

The mount is an essential implant component which is used to insert the fixture in the alveolar bone. It is important that the mounts be made of titanium in order not to modify implant surface properties. In the technique reported here two mounts are required: the first is used as an abutment for the provisional restoration in resin; the second is used early as a transfer during the impression and then as abutment for the definitive metal-ceramic crown. Titanium abutments can be modified both in shape and size in order to obtain custom abutments capable of adequately supporting both a 
provisional and a definitive crown. They allow a reduction in total costs as a result of the non-use of healing abutments, transfers and prosthetic abutments, but also prove aesthetically satisfying.

In the present case report and in another five clinical cases treated using the same technique, no evidence of complications at the abutment-implant interface or at the abutment-crown interface have been reported [34]. The implant/abutment interface represents a crucial element for maintaining the structural stability of the implant restoration and preventing mechanical problems capable of compromising the long-term success of the implant treatment $[35,36]$.

A number of studies indicate that there is no evidence of different responses and behavior of the peri-implant marginal bone and soft tissue when titanium or gold-alloy abutments are used in conjunction with cemented single-tooth implant restorations [37].

The choice of a metal-ceramic crown was based on the patient's limited economic resources as well as on his limited aesthetic requirements as a result of his poor general oral condition (tartar, smoking, discolorations). It was, however, possible to obtain a prosthesis integrated aesthetically and biologically with the remaining denture. The prosthesis presents a natural appearance without dark or opaque gingival margins due to metal prosthetic margins covered by gingival tissue (architecture and biotype).

\section{CONCLUSIONS}

This case report illustrates a simplified postextraction implant placement technique which can be used in order to obtain acceptable aesthetic outcomes and reduce the cost to the patient. Immediately loaded postextraction implants may be employed to rehabilitate patients of low economic status, thus enabling implantology and its advantages to be extended to a wider range of patients. The patient's desires, in terms of aesthetic and functional rehabilitation, were satisfied using a technique that appears to be reliable. Prospective randomised controlled studies are necessary to confirm the predictability and reproducibility of this procedure.

\section{ACKNOWLEDGEMENTS}

The authors have no financial interest in any company or in any of the products mentioned in this article. The authors wish to thank Anthony Steele, former Senior Lecturer in Medical English, University of Verona, for his invaluable assistance with the linguistic editing of this paper.

\section{CONFLICT OF INTEREST}

The author confirms that this article content has no conflicts of interest.

\section{REFERENCES}

[1] Brånemark PI, Hansson $\mathrm{BO}$, Adell R, et al. Osseointegrated implants in the treatment of the edentulous jaw. experience from a 10year period. Scand J Plast Reconstr 1977; 16: 1-132.

[2] Albrektsson T, Brånemark PI. A 15-year study of osseointegrated implants in the treatment of the edentoulus jaw. Int J Oral Maxillofac Implants 1990; 5: 347-59.

[3] Zarb GA, Zarb FL. Tissue integrated dental prostheses. Quintessence Int 1985; 16: 39-42.
[4] Wohrle PS. Single-tooth replacement in the aesthetic zone with immediate provisionalization: fourteen consecutive case reports. Pract Periodontics Aesthet Dent 1998; 10: 1107-14.

[5] Schropp L, Isidor F, Kostopoulos L, et al. Patient experience of and satisfaction with, delayed-immediate vs. delayed single-tooth implant placement. Clin Oral Res 2004; 15: 498-503.

[6] Huys LW. Replacement therapy and the immediate post-extraction dental implant. Implant Dent 2001; 10: 93-102.

[7] Saadoun AP. Immediate implant placement and temporization in extraction and healing sites. Compend Contin Educ Dent 2002; 23: 309-26.

[8] Chen ST, Wilson TG Jr, Hammerle CH. Immediate or early placement of implants following tooth extraction: review of biologic basis, clinical procedures, and outcomes. Int J Oral Maxillofac Implants 2004; 19: 12-25.

[9] Schropp L, Kostopoulos, L, Wenzel A. Bone healing following immediate versus delayed placement of titanium implants into extraction sockets: a prospective clinical study. Int J Oral Maxillofacial Implants 2003; 18: 189-99.

[10] C Pinho MN, Roriz VL, Novaes AB Jr, et al. Titanium membranes in prevention of alveolar collapse after tooth extraction. Implant Dent 2006; 15: 53-61.

[11] Schropp L, Wenzel A, Kostopoulos L, et al. Bone healing and soft tissue contour changes following single-tooth extraction: a clinical and radiographic 12-month prospective study. Int J Periodontics Restorative Dent 2003; 23: 313-23.

[12] Lang NP, Tonetti MS, Suvan JE, et al. Immediate implant placement with transmucosal healing in areas of aesthetic priority: a multicentre randomized-controlled clinical trial I. surgical outcomes. Clin Oral Implants Res 2007; 18: 188-96.

[13] Matin K, Senpuku H, Hanada N, Ozawa H, Ejiri S. Bone regeneration by recombinant human bone morphogenetic protein-2 around immediate implant. Int J Oral Maxillofac Implants 2003; 18: 211-7.

[14] Schwartz AD, Chaushu G. Placement of implants into fresh extraction sites: 4 to 7 years retrospective evaluation of 95 immediate implants. J Periodontol 1997; 68: 1110-6.

[15] Sakoh J, Wahlmann U, Stender E, et al. Primary stability of a conical implant and a hybrid, cylindric screw-type implant in vitro. Int J Oral Maxillofac Implants 2006; 21: 560-6.

[16] Bachter A, Joss U, Wiesmann HP, et al. Biological and biomechanical evaluation of interface reaction at conical screw-type implants. Head Face Med 2006; 2: 5-21.

[17] Colomina LE. Immediate loading of implant-fixed mandibular prostheses: a prospective 18-month follow-up clinical study-preliminary report. Implant Dent 2001; 10: 23-9.

[18] Vanden BL, Rangert B, Wendehag I. Immediate/earlyfunction of Brånemark System TiUniteimplants in freshextractionsockets in maxillae and posteriormandibles: an 18-month prospectiveclinicalstudy. Clin Implant Dent Relat Res 2005; 7: 121-30.

[19] Cornellini R, Cangini F, Covani U, et al. Immediate restoration of implant placed into fresh extraction socket for single-tooth replacement: a prospective clinical study. Int J Periodontics Restorative Dent 2005; 25: 439-77.

[20] Schwartz-Arad D, Laviv A, Levin L. Survival of immediately provisionalized dental implants placed immediately into fresh extraction sockets. J Periodontol 2007; 78: 219-33.

[21] Sammartino G, Marenzi G, Espedito di Lauro A, et al. Aesthetics in oral implantology: biological, clinical, surgical, and prosthetic aspects. Implant Dent 2007; 16: 54-65.

[22] Somanathan RV, Sim nek A, Bukac J, et al. Soft tissue esthetics in implant dentistry. Acta Medica (Hradec Kralove) 2007; 50: 1836.

[23] Matthias RE, Atchison KA, Schweitzer SO, et al. Comparisons between dentist ratings and self-ratings of dental appearance in an elderly population. Spec Care Dentist 1993; 13: 53-60.

[24] Fradeani M. Constructing and finalizing the prosthetic rehabilitation. In: Fradeani M, Barducci G, Eds. Esthetic rehabilitation in fixed prosthodontics, Volume 2 - Prosthetic Treatment: A Systematic Approach to Esthetic, Biologic, and Functional Integration. Chicago: Quintessence 2008. vol. 2.

[25] Vallittu PK, Vallittu AS, Lassila VP. Dental aesthetics: a survey of the attitudes in different groups of patients. J Dent 1996; 24: 335-8. Chen S, Darby I, Reynolds E. A prospective clinical study of nonsubmerged immediate implants: clinical outcomes and aesthetic results. Clin Oral Implants Res 2007; 18: 552-62. 
[27] Papaspyridakos, Lal K. Flapless implant placement: a technique to eliminate the need for a removable interim prosthesis. J Prosthet Dent 2008; 100: 232-5.

[28] Kinsel RP, Capoferri D. A simplified method to develop optimal gingival contours for the single implant-supported, metal-ceramic crown in the aesthetic zone. Pract Proced Aesthet Dent 2008; 20: 231-6.

[29] Ormianer Z, Palti A. Retrospective clinical evaluation of tapered screw-vent implants: results after up to eight years of clinical function. J Oral Implantol 2008; 34: 150-60.

[30] Morris HF, Winkler S, Ochi S, et al. A new implant designed to maximize contact with trabecular bone: survival to 18 months. J Oral Implantol 2001; 27: 164-73.

[31] Khayat PG, Milliez SN. Prospective clinical evaluation of 835 multithreaded tapered screw-vent implants: results after two years of functional loading. J Oral Implantol 2007; 33: 225-31.

[32] You TM, Choi BH, Li J, Xuan F, et al. Morphogenesis of the periimplant mucosa: a comparison between flap and flapless proce- dures in the canine mandible. Oral Surg Oral Med Oral Pathol Oral Radiol Endod 2009; 107: 66-70.

[33] Blanco J, Nunez V, Aracil L, et al. Ridge alterations following immediate implant placement in the dog: flap versus flapless surgery. J Clin Periodontol 2008; 35: 640-8.

[34] Jung RE, Pjetursson BE, Glauser R, et al. A systematic review of the 5-year survival and complication rates of implant-supported single crowns. Clin Oral Implants Res 2008; 19: 119-30.

[35] Bambini F, Mema L, Pellecchia M, et al. Comparative analysis of deformation of two implant/abutment connection systems during implant insertion: an in vitro study. Minerva Stomatol 2005; 54: 129-38.

[36] Oates TW. Influence of the microgap in the peri-implant hard and soft tissues: a histomorphometric study in dogs. Implant Dent 2003; 12: 10 .

[37] Vigolo P, Givani A, Majozub Z, et al. A 4-year prospective study to assess peri-implant hard and soft tissue adjacent to titanium versus gold-alloy abutments in cemented single implant crowns. J Prosthodont 2006; 15: 250-6.

(C) Scala et al.; Licensee Bentham Open .

This is an open access article licensed under the terms of the Creative Commons Attribution Non-Commercial License (http://creativecommons.org/licenses/by-nc/3.0/) which permits unrestricted, non-commercial use, distribution and reproduction in any medium, provided the work is properly cited. 